\title{
AULA INAUGURAL
}

\section{O DESAFIO QUE A TEORIA SISTEMÁTICO- ESTRUTURAL DE PUNTEL COLOCA À FILOSOFIA ATUAL ${ }^{1}$}

\author{
F. Javier Herrero ${ }^{2}$ \\ herrero@faculdadejesuita.edu.br
}

A escolha deste tema se deve a vários fatores que confluem neste momento e que constituem um problema sumamente importante na atualidade e, portanto, provocam um grande desafio à filosofia atual. Em primeiro lugar, a publicação de duas grandes obras do Professor Lorenz B. Puntel: Estrutura e Ser. Um quadro referencial teórico para uma filosofia sistemática ${ }^{3}$, e Ser e Deus. Um enfoque sistemático em confronto com M. Heidegger, É. Lévinas e J.-L.Marion ${ }^{4}$. Trata-se de dois livros, não só voluminosos, (o primeiro tem 658pág, o segundo 383p.), mas de uma obra que podemos caracterizar, inicialmente, como a obra de uma vida dedicada à filosofia, projetada com esmero, perseguida pacientemente e coroada com um sucesso inquestionável. Não é por acaso que Puntel recebeu em 2010 o Findlay Book Prize concedido pela Metaphysical Society of America, para o melhor livro de filosofia, publicado nos Estados Unidos nos últimos dez anos. O segundo fator é o contraste que esta obra mostra e provoca com a situação atual da filosofia.

Há dois elementos na filosofia atual que chamam a atenção, ambos constituindo um problema que pode assumir graves proporções. Um primeiro

1 Aula inaugural do Departamento de Filosofia da UFMG proferida no dia 29 de março de 2012.

2 Professor da Faculdade Jesuíta de Filosofia e Teologia (FAJE) de Belo Horizonte.

3 São Leopoldo, Editora Unisinos, 2008. Tradução do alemão: Struktur und Sein. Ein Theorierahmen für eine systematische Philosophie, Mohr Siebeck Tübingen, 2006.(Sigla ES)

4 São Leopoldo, Editora Unisinos, 2011. Tradução do alemão: Sein und Gott:ein systematischer Ansatz in Auseinandersetzung mit M. Heidegger, E. Lévinas und J.-L. Marion, Mohr Siebeck,Tübingen, 2010.(Sigla $\mathrm{SeD})$ 
é a especialização que a filosofia vai adotando seguindo nisso uma tendência da sociedade moderna e das ciências empíricas. E aqui aparece um primeiro aspecto do contraste que esta obra mostra. Toda especialização leva consigo um lado positivo e um lado negativo. O positivo consiste em que se aprofunda um aspecto, um âmbito, um tema, enfim, um objeto que passa a ser tratado com meios mais sofisticados, que possibilitam novas descobertas, que abrem novas perspectivas. No caso da ciência, isso significa, entre outras coisas, que cada descoberta se traduz em novas tecnologias, que transformam paulatinamente toda uma forma de vida. O lado negativo surge como consequência imediata do anterior. No caso da ciência, uma especialização, que amplia o conhecimento do objeto escolhido, leva consigo um maior desconhecimento dos outros âmbitos, um maior distanciamento do todo, a final, se diz, não é possível ser especialista em tudo, i .é, conhecer tudo.

A obra de Puntel contrasta com e desafia essa tendência à especialização, no sentido indicado, na medida em que ela recupera a característica principal da tradição filosófica, que consiste em tematizar o todo, em elaborar uma teoria do todo, que tradicionalmente assumiu o nome de uma teoria do Ser. E ela faz isso sem renunciar a um rigor verdadeiramente exemplar.

Um segundo elemento da filosofia atual, que é consequência do anterior (da especialização), é a fragmentação que ela produz nos enfoques filosóficos. Cada enfoque mostra apenas um fragmento ou, como se costuma dizer, uma aproximação. Mas o característico dessa fragmentação é que ela é defendida como algo inevitável e que leva consigo a consequência de que a tematização do todo é impossível. Se a tematização do fragmento já é difícil e deixa sempre problemas sem resolver, o, que dizer então da tematização do todo, do ser? A partir dessa dificuldade particular se conclui que a tematização do todo é impossível. Abandonam-se então os critérios que possibilitavam a tematização do ser, estabelecem-se critérios restritos para cada âmbito ou enfoque, surgindo assim uma pura pluralidade de enfoques filosóficos que, obviamente, só podem ter um valor relativo, mas que leva a muitos a concluir ao relativismo puro e simples de toda concepção filosófica. Mas a partir dessa situação surge um fenômeno curioso. Aparentemente a filosofia se contenta com o fragmento, mas na realidade não é isso que acontece. Porque se chega a proibir ir além do fragmento. Parece que a impossibilidade de tematizar o todo se traduz na proibição de ir além de uma perspectiva. Mas sabemos que toda proibição provoca sua transgressão, o que significa, como mínimo, que é possível ir além dela, que de fato já sempre fomos além do limite, ao estabelecer a proibição. Isso significa que a elevação ao todo é uma característica inquestionável e inalienável do ser humano. E significa também que as dificuldades que 
surgem na tematização de um âmbito ou objeto restrito não impossibilitam necessariamente a tematização do todo. Paradoxalmente, poderíamos afirmar o contrário. É a capacidade do ser humano de ir sempre além, de superar todo limite, sem eliminá-lo, que possibilita a especialização e a busca de meios sofisticados para enfrentar as dificuldades específicas de cada âmbito restrito.

A obra de Puntel contrasta com e desafia esta tendência à fragmentação da filosofia atual, na medida em que faz dessa peculiaridade do ser humano, de elevar-se sempre ao todo, chame-se esta característica como se quiser, (ser radicalmente aberto, abertura ao ser, coextensividade intencional com o Ser) a mola propulsora de todo seu empreendimento teórico. Em cada etapa de seu desenvolvimento encontramos uma referência a esta característica do ser humano. Cada nova tarefa, nos diz, é não só possível, mas irrenunciável, porque essa possibilidade faz parte das potencialidades do espírito humano inscritas na sua coextensividade intencional com o Ser.

E o admirável na sua tematização do todo, de sua teoria do Ser, é que ele o faz com todos os meios e recursos conceituais que a filosofia atual oferece. Podemos dizer que não há problema que a filosofia atual enfrente, seja a filosofia analítica, seja a filosofia continental, que não seja tratado, amplamente discutido e resolvido na medida em que seja significativo para a teoria do Ser. Puntel mostra um conhecimento invejável de todos os problemas atuais e dos recursos conceituais com os quais são enfrentados. E a complexidade dos problemas e a sofisticação dos meios conceituais não impede que ele mantenha uma clareza impressionante em todo o seu desenvolvimento. Ele não perde essa clareza mesmo quando usa um dos meios conceituais mais sofisticados como é a formalização própria de uma parte da filosofia analítica. Na hora de resumir a discussão, de tirar as consequências ou resultados dela, o leitor encontra formulações suficientemente claras da força dos argumentos empregados e das conclusões conseguidas. Não tenho, pois, a menor dúvida de que a obra de Puntel constitui um enorme desafio a essa especialização e fragmentação em que a filosofia atual se encontra. E o constitui na medida em que explora de modo admirável a força crítica dessa elevação ao todo que constitui a mais nobre característica do ser humano, e que a filosofia clássica consagrou, desde seus inícios, nas suas tentativas de tematizar o Ser, porque a elevação ao todo, tematizada teoricamente, potencializa ao máximo a força crítica referida e dirigida ao todo. A maior conquista, poderíamos dizer, dessa tematização do Ser é a atualização da força crítica em relação ao todo e a todas as teorias parciais, e da capacidade da atividade teórica própria da filosofia.

Há outro ponto que me parece não só digno de menção, mas que valoriza de modo especial a sua teoria do Ser. O segundo livro mencionado "Ser e 
Deus", não trata apenas de um tema que foi objeto da filosofia tradicional, o problema de Deus, mas que depois, talvez por causa da mesma fragmentação da filosofia, deixou de ser importante, ele trata de Ser $e$ Deus, i. é, da relação de Ser e Deus. Essa relação mostra o sentido último e completo do problema do Ser e da importância decisiva desta tematização. Alguém poderia perguntar: a final por que tematizar o Ser? Se o problema de Deus deixou de ser um problema filosófico, que conseguiríamos com a tematização do Ser? A tese de Puntel é: Deus é o ponto de chegada da concepção plenamente desdobrada do Ser. Deus é então o Ser plenamente explicitado ou, com outras palavras, "Ser em toda a sua plenitude"s. Todas as perguntas sobre a vida humana, sobre o universo, enfim sobre o Ser, adquirem então um significado diferente que nos atinge, queiramos ou não, e que aqui recebem uma resposta á altura das circunstâncias. Porque a questão de Deus só pode ser esclarecida no quadro de uma concepção "compreensiva da realidade", o que para ele significa que "perguntar por Deus, tratar efetivamente da questão e dar uma resposta racional em todos os seus aspectos só tem sentido.... se acontecer no quadro de uma concepção.... do Ser como tal e em seu todo"6. Se Deus é Ser em toda a sua plenitude, se Deus só pode ser esclarecido no quadro de uma concepção compreensiva da realidade, i. é, tem a ver com o todo, então não podemos simplesmente desinteressar-nos da questão do Ser, porque agora aparece o porquê último e pleno daquela característica peculiar do ser humano de ser intencionalmente coextensivo com o Ser como tal e em seu todo. Perguntar por tudo, perguntar pelo Ser, perguntar pelas modalidades do Ser é uma das maiores potencialidades de inteligibilidade do pensamento humano, porque elas são, no fundo, modos pelos quais se manifesta o Ser propriamente dito ${ }^{7}$.

Evidentemente não é possível expor aqui a teoria do Ser em seu todo. Terei que me limitar a indicar os grandes $\operatorname{passos}^{8}$, com algum comentário.

\section{Pressupostos atuais da teoria do Ser}

Poderia elencar alguns pressupostos que Puntel supõe e constituem sua teoria. Se na atualidade se supõe como impossível uma teoria do Ser, é preciso salientar, de saída, que Puntel mostra, como já foi dito, com todos os meios da filosofia atual que essa teoria é possível e o faz apresentando a teoria

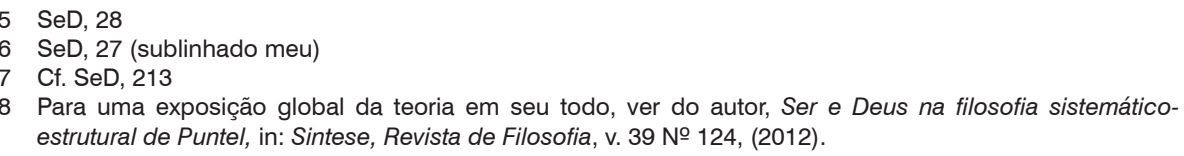
estrutural de Puntel, in: Sintese, Revista de Filosofia, v. 39 № 124, (2012). 
plenamente desenvolvida e justificada. Outro pressuposto atual que se opõe a ela seria a "virada linguística", que não permitiria sair da linguagem. É preciso dizer que Puntel realiza a virada linguística, mas o faz, não ficando a meio caminho, mas levando-a até o pleno desenvolvimento. Abreviando, podemos dizer, a linguagem é "medium" natural (no sentido de mediação) de todo o desenvolvimento da teoria, mas essa mediação imprescindível supõe um último pressuposto inquestionável, a expressabilidade do Ser. Justamente a linguagem é a instância que o expressa, de forma que poderíamos dizer que sem linguagem nada seria dado à teoria, nada poderia ser expresso e articulado pela teoria, ou dito de outro modo, puras coisas sem qualquer linguagem seriam opacas, pura linguagem sem coisas seria vazia. E uma linguagem expressante que nada expressa é um grande contrassenso. E se é próprio da linguagem expressar, não podemos ficar a meio caminho na amplíssima tarefa de expressar, como seria por ex. ficando num modo de expressão que é a expressão da linguagem natural. Ao contrário, à expressabilidade universal do Ser deve corresponder uma linguagem igualmente universal que, consequentemente, deve ser entendida "como um sistema semiótico composto de uma quantidade infinita não enumerável de expressões". E se ela é assim compreendida, então a linguagem "nada mais é do que o "reverso" ou o "inverso" da expressabilidade universal do mundo".

Puntel desenvolve a linguagem filosófica que é a linguagem da teoria, que justamente pergunta por tudo e pelo todo. Essa é uma grande característica do ser humano, perguntar por tudo, ou alguém pode pôr um limite apriorístico a essa capacidade? Em virtude de que? A riqueza de Puntel é mostrar, de fato, que a linguagem teórica pode tematizar o Ser como tal e em seu todo, recuperando assim a função própria da filosofia que consiste na elaboração de teorias e da teoria do Ser.

\section{O que se entende por filosofia sistemática?}

Um primeiro passo importante da teoria do Ser é o ponto de partida. Ela parte de um fato absolutamente fundamental para todo empreendimento teórico. Todo ser humano, quando profere uma sentença teórica, nunca começa sua reflexão partindo apenas dela (mesmo que ele ache que é assim), pois para que essa sentença seja inteligível é necessário que todos, falantes e ouvintes, façam uma enorme quantidade de pressuposições que justamente possibilitam o significado dela. É necessário pressupor uma linguagem (a sentença é proferida numa linguagem específica), uma lógica, (as palavras da sentença seguem uma 
determinada ordem e se referem a certas conexões de raciocínios conhecidas e consideradas corretas), uma semântica (a sentença dá às palavras que a compõem um significado e um valor semântico específico), e uma ontologia (o enunciado se refere a algo da realidade, supõe-se, de modo implícito, o que é a realidade, o que são os entes, o Ser). Sem essas pressuposições básicas, não é possível compreender nada, tudo permaneceria vago e indeterminado. Isso significa: todas essas pressuposições se fazem dentro de um quadro referencial teórico. Portanto, tudo o que se possa denominar de "teórico" só tem sentido se estiver situado dentro de um quadro referencial teórico, que é o conjunto de todos os elementos pressupostos por uma teoria.

Esse ponto de partida nos leva a reconhecer que sempre estamos pressupondo, queiramos ou não, um quadro referencial teórico e que quando não o tematizamos expressamente, corremos o risco de fazer afirmações falsas ou, ao menos, não justificadas. Naturalmente, a tematização do quadro referencial teórico leva consigo alguns problemas específicos que Puntel discute com grande maestria.

Ora, como o quadro referencial teórico é para elaborar uma filosofia sistemática, é necessário esclarecer o que se entende por esta última. $\mathrm{O}$ autor dá uma quase definição em sentido programático. "Filosofia sistemáticoestrutural é a teoria das estruturas universais (mais gerais) do ilimitado universo do discurso" "10. Dois grandes elementos constituem essa definição inicial: "teoria das estruturas universais" e "ilimitado universo do discurso".

O conceito de estrutura é tomado da matemática, mas aqui é ampliado para fins filosóficos. Na filosofia sistemática do autor, todos os elementos teóricos podem ser reduzidos ao conceito central de estrutura. Não há nenhuma "entidade", por mais simples e mais básica que seja, que não seja estrutura. Tudo é estrutura. Em termos intuitivos, "a estrutura pode ser caracterizada como inter-relação diferenciada e ordenada ou como relação e interação de elementos de uma entidade" ". Nesse sentido, ela é uma noção ou "fator original" em todo empreendimento teórico. ( $\mathrm{Na}$ tradição filosófica se falava de categorias). As estruturas universais são as estruturas que articulam o ilimitado universo do discurso. $\mathrm{O}$ exame compreensivo de todos os elementos que entram em jogo em uma teoria filosófica mostra que há três tipos de estruturas fundamentais: as lógico-formais (lógicas e matemáticas), as semânticas e as ontológicas.

$\mathrm{O}$ segundo elemento da definição é o ilimitado universo do discurso. $\mathrm{O}$ que se entende por ele? Negativamente, poderíamos dizer: não há nada, do 
qual não se possa falar, indagar, questionar, teorizar. Nesse sentido é ilimitado. Positivamente, o universo do discurso pode ser entendido como a totalidade do que é "dado". Nesse sentido, o termo dado é o ponto de partida do empreendimento teórico. A tarefa da filosofia consiste em articular as relações entre as estruturas e o universo do discurso. Tarefa que pode ser entendida de ambos os lados: ou aplicando as estruturas ao universo do discurso ou inserindo o universo do discurso na dimensão das estruturas.

\section{O Ser como interconexão entre o quadro referencial teórico e ili- mitado universo do discurso ou entre estruturas e o ser objetivo.}

O segundo passo da teoria do Ser é descobrir o Ser na unidade dessas duas dimensões (quadro teórico e ilimitado universo do discurso).

3.1. O quadro referencial teórico é constituído por uma linguagem, uma semântica e uma ontologia. A linguagem é o medium natural e imprescindível para a apresentação teórica. Mas trata-se de uma linguagem capaz de exprimir adequadamente todos os elementos teóricos. Essa não pode ser a linguagem natural, porque embora esta possua um segmento "teórico", ela está voltada primordialmente para a comunicação, o qual a torna muito indeterminada e imprecisa para fins teóricos. Terá que ser a linguagem filosófica. Está terá que exprimir as estruturas formais (lógicomatemáticas), as estruturas semânticas e as estruturas ontológicas. As estruturas formais são as mais gerais, irrestritamente universais, pois elas constituem a textura interna de cada discurso e de cada item ontológico. As estruturas semânticas expressam o lugar central que a linguagem ocupa no quadro teórico. Elas configuram a relação linguagem-mundo. Como a linguagem filosófica é puramente teórica, a semântica que entra em questão será aquela que satisfaz ás exigências teóricas. Elemento chave na teoria do Puntel é a relação entre as estruturas semânticas e as ontológicas. Quando as estruturas semânticas primas (que são as proposições primas expressas pelas sentenças primas) são plenamente determinadas elas se revelam idênticas ao plano ontológico. Semântica e ontologia são os dois lados de uma e mesma moeda. Assim, as estruturas ontológicas são a expressão do ponto final do discurso teórico-filosófico. Que semântica e que ontologia é defendida então por Puntel?

Uma vez que recusou a linguagem natural como o medium de apresentação teórica, Puntel recusa também a semântica e a ontologia da substancia ligadas a ela. A razão principal é que os filósofos que empregam a linguagem 
natural se valem da lógica dos predicados de primeira ordem como quadro teórico. E a semântica da linguagem lógico-predicativa se apoia fundamental e inteiramente no princípio da composicionalidade ${ }^{12}$. Ora, este princípio implica que os valores semânticos dos componentes subsentenciais tenham uma independência ao menos relativa. O problema que surge pela predicação no plano da linguagem predicativa de primeira ordem é que se atribui um predicado a uma entidade (sujeito ou substrato) que é sempre pressuposta. Ora, o ponto chave é que essa entidade não é inteligível, pois ela, em virtude do pressuposto estabelecido, tem que ser algo que como tal possibilite a predicação de todo tipo de universais (das propriedades e relações). Mas o que seria essa entidade pressuposta? Se abstraímos de todas as determinações que lhe possam ser atribuídas e de todas as entidades com as quais possa entrar em relação, (e podemos abstrair pois por hipótese se trata de uma entidade própria), o que resta dela? Uma entidade sem qualquer determinação, completamente vazia, não é, pois, inteligível e, por isso, tem que ser rejeitada ${ }^{13}$.Isso significa: a estrutura das sentenças qualificáveis como filosoficamente adequadas não pode ter a forma de sujeito e predicado. E, consequentemente, não é aceitável a "semântica composicional"14.

A semântica defendida pelo autor é a semântica contextual. Ele parte do princípio do contexto, introduzido por Frege no início da "virada linguística", que acarretou uma mudança profunda na filosofia. O princípio diz: "Somente no contexto de uma sentença as palavras significam algo" ${ }^{15}$ Esse princípio confere às sentenças o primado semântico, o que implica também que "a sentença expressa um pensamento"16. Puntel reinterpreta o princípio do contexto assim:"Somente no contexto de uma sentença as expressões linguísticas possuem valor semântico" ${ }^{17}$ Este princípio é entendido na sua

12 "O significado (ou valor semântico) da sentença é uma função dos significados (ou dos valores semânticos) de seus componentes subsentenciais" (ES, 257)

13 Cf. para toda a crítica da ontologia da substância, ver ES, 252-254 e 258-264

14 A semântica composicional, que foi predominante em toda a história da filosofia e hoje é defendida por quase todos os filósofos analíticos, resulta do princípio da composicionalidade, que compreende a sentença com a estrutura de sujeito e predicado, implicando uma ontologia da substância.

15 Frege G., Die Grundlagen der Aritmetik, § 62.Breslau: Koebner, 1884. Edição do centenário por C. Thiel, com textos complementares, Hamburg, Meiner, 1986

16 Frege, G., Der Gedanke. Beiträge zur Philosophie des deutschen Idealismus 1, 1918-1919.Cit cf. Frege, G., Logische Untersuchungen, Ed. e introd. por G. Patzig, Göttingen:Vandenhoeck \& Ruprecht, $2^{\mathrm{a}}$ ed de 1976 , p. 33

17 ES, 266 (SeD, 215). Este princípio implica também que pensamento é sinônimo de proposição. Como ele mesmo diz: "as expressões "pensamento", "proposição", "estado de coisas" são entendidas e empregadas como sinônimas" (ES, 215). Isso significa que o autor rejeita a concepção de que conceitos são fatores mentalistas originais que não podem ser reduzidos a alguma outra coisa. "Pelo contrário, ele os entende e explica como abreviações coloquial-naturais e cômodas de sentenças que, por sua vez, expressam proposições".(SeD, 339) 
versão forte, que vai além de Frege, i. é, só são admitidas sentenças primas sem a estrutura de sujeito e predicado. Sentenças primas exprimem uma forma específica de proposição: uma proposição prima. Esta é o conteúdo informativo ou expressum da sentença prima, mais em concreto, ela é o que expressa o verbo que ocorre na sentença prima, por ex. "chove", que é uma sentença sem sujeito e predicado.

A semântica contextual reformula a sentença com sujeito e predicado da seguinte maneira. Por ex. na sentença: "Sócrates é filósofo", o nome próprio é uma abreviação de um grande número de sentenças primas como: "é o caso (ou acontece) de ser grego", "é o caso (ou acontece) de ter nascido no ano 470 a.C.", é o caso (ou acontece) de ter sido mestre de Platão, etc. O predicado “... é filósofo" é mais uma abreviação de uma sentença prima: "é o caso (ou acontece) de ser filósofo", a qual exprime uma proposição prima (ser filósofo) pertencente à totalidade de proposições primas que constituem o que o nome "Sócrates" abreviadamente designa.

O que é então uma sentença teórica? Se a estrutura das sentenças não pode ter a forma de sujeito e predicado, qual será a forma aceitável? Toda sentença, seja teórica, prática ou estética, só pode ser compreendida em seu caráter específico, quando se atende ao determinado operador, que é anteposto à sentença de modo explícito ou implícito. O operador é uma função que toma a sentença ainda não especificada como argumento e que tem uma determinada imagem como valor. O valor é a sentença totalmente especificada em seu caráter teórico. O operador teórico pode ser expresso assim: “...é o caso que chove"18, e a estrutura da sentença formalizada assim: $(\mathbf{T})(\varphi)$, sendo (T) o operador teórico e $(\varphi)$ a variável de uma sentença.

Porém, a proposição prima é uma entidade ainda insuficientemente determinada, i. é, subdeterminada, ou ainda não completamente determinada. As proposições primas precisam de uma qualificação para se tornarem completamente determinadas. Essa qualificação é dada pelo conceito de verdade. O termo "verdade(iro)" é a expressão central da semântica. Por isso, a semântica contextual parte de um "fato linguístico original: a indeterminidade (ou subdeterminidade) versus a determinidade da linguagem" ${ }^{19}$. Esclarecer o conceito de verdade significa esclarecer o fenômeno da indeterminidade e da determinidade completa da linguagem.

18 A expressão "é o caso que" traduz de modo deficiente a famosa formulação de Wittgenstein no Tractatus: "Die allgemeine Form des Satzes ist: es verhält sich so und so" (a forma geral da sentença é: é o caso de ser assim e assim).

19 ES, 196 
A determinação da linguagem ocorre em três planos. O $1^{\circ}$ plano é o contextual cotidiano. Nele a linguagem é simplesmente usada. Ela é determinada por uma dimensão externa à linguagem: o contexto cotidiano. Essa determinidade não é a teórica, científica, filosófica, porque não é ainda avaliada, explicitada. O operador do contexto é: "Está contextualmente dado" que (a neve é branca). O $2^{\circ}$ plano é o pragmático-linguístico. Neste ocorre uma modificação que se articula assim: eu afirmo que p. A sentença singular recebe sua determinação semântica através de um fator externo à linguagem (uma ação) e um fator interno à linguagem (a articulação linguística dessa ação). O $3^{\circ}$ plano é o semântico onde acontece o operador verdade(iro): "é verdade que p" . Este operador é puramente interno à linguagem, é o determinante interno propriamente dito. A inter-relação dos três planos de determinação linguística mostra que o plano semântico é o fundamental, porque os outros dois dependem dele. Pelo contrário, no plano semântico, a linguagem não depende de nenhum fator externo a ela. A linguagem fala sobre si mesma, qualifica, determina a si própria. Assim, num primeiro momento, a palavra "verdade(iro)" é interpretada como o operador "é verdade que" e designa tanto a passagem da linguagem de um estatuto indeterminado para um estatuto completamente determinado quanto o resultado da passagem: a linguagem completamente determinada ${ }^{20}$.

Mas como entender esse estatuto plenamente determinado da linguagem em geral? A resposta é: “o estatuto plenamente determinado da linguagem não se refere nem mais nem menos do que à dimensão ontológica plena da linguagem " ${ }^{21}$. Puntel não entende a referência ontológica do operador verdade como a teoria da correspondência, mas, de certo modo, preserva a sua ideia básica. O argumento fundamental do operador da verdade: "é verdade que", é a proposição expressa por uma sentença declarativa. A definição da verdade de uma sentença dependerá, então, da verdade da proposição expressa pela sentença. Uma sentença é verdadeira exatamente quando expressa uma proposição verdadeira. Mas o que é uma proposição verdadeira?

Uma proposição verdadeira é "nada mais nada menos e nada distinto que um componente do mundo real" 22 . Se chamarmos de "fato" o componente intencionado com uma proposição verdadeira, "a proposição verdadeira e o fato são uma e mesma entidade" ${ }^{23}$. Assim, a ideia fundamental de verdade, 
num segundo momento, é a referência ontológica de verdade(iro) como identidade de proposição e fato ${ }^{24}$.

Como pensar então a ontologia em perfeita coerência com a teoria da verdade ontológico-semântica? Foi dito antes que as estruturas ontológicas são a expressão do ponto final ou o estatuto definitivo das estruturas semânticas. Daí resulta que a estrutura ontológica é a proposição prima completamente determinada ou realizada. Mais exatamente, a uma proposição prima semântica, quando ela obtém o estatuto de verdade, i. é, quando possui um estatuto definitivo, corresponde um fato primo, sendo que aqui se trata de um caso-limite de "correspondência" interpretado como identidade (de proposição prima plenamente determinada e fato primo). Fatos primos são concebidos como estruturas primas ontológicas. Daí resulta a tese central da nova ontologia: "o mundo é a totalidade dos fatos primos como estruturas primas ontológicas expressáveis" ${ }^{25}$. Agora podemos ver em que sentido as estruturas lógicas e matemáticas são ontológicas. Elas possuem um estatuto rigorosamente ontológico, quando são "aplicadas" a fatos primos ou estruturas primas, i. é, quando "estruturam" essas entidades. A razão é que quando se compreende o mundo como a totalidade dos fatos primos (e não das coisas) configurados com extrema complexidade e variedade, as estruturas lógicas e matemáticas constituem os fatores que configuram os fatos primos. ${ }^{26}$ Temos, assim, uma coerência perfeita entre os três tipos de estruturas. E verdade não é mais do que o estatuto completamente determinado da interconexão dos três tipos de estruturas.

E se agora formulamos de modo geral a relação entre a linguagem teórica e o mundo, podemos dizer: uma linguagem teórica abrangente completamente elucidada compreende ou articula o mundo mesmo, a realidade mesma. Este enfoque novo se orienta pela ideia de adequação crescente da apreensão ou articulação do mundo, da realidade como tal. ${ }^{27}$ É muito importante captar o alcance desta ideia central que supõe que semântica e ontologia estão numa relação fundamental de interconexão recíproca.

Essa interconexão recíproca ou adequação crescente da apreensão da realidade como tal implica, em primeiro lugar, que tudo, i. é, conhecimentos, teorias, ciências, portanto também filosofia, só podem ser adequadamente compreendidos e desenvolvidos se toda a dimensão teórica 
for ontologizada. ${ }^{28}$ Isso significa: não só os sujeitos cognoscentes, os teóricos, mas também toda a dimensão teórica no sentido objetivo (a dimensão dos conceitos, das sentenças, das teorias, etc), deve ser vista como parte da natureza (do mundo, do universo, do Ser em seu todo). Se percebemos bem, estamos dizendo com isso que a ontologização da dimensão teórica implica, consequentemente, a superação do abismo total (presente em grande parte da filosofia atual) ou cesura entre o sujeito (cognoscente ou teórico) $e$ a natureza, o mundo, o Ser em seu todo, ou entre sujeito/subjetividade-pensamento-espíritolinguagem (teorias...), de um lado, e, de outro, o "sistema" ou qualquer outra designação que se use para designar a realidade, o mundo, o universo, o Ser (em seu todo). ${ }^{29}$. Pois seja o que for esta última dimensão que se costuma chamar de "sistema", "mundo (universo, Ser)", em qualquer hipótese, ela possui uma estruturalidade genuinamente ontológica imanente fundamental, i. é, expressabilidade completa ${ }^{30}$. Sem esta tese ontológica central, absolutamente nada se poderia tornar compreensível referente à linguagem, teoria, verdade, etc. Por outro lado, a afirmação da superação do abismo indicado não é mais do que uma implicação de um truísmo ${ }^{31}$ fundamental afirmado pela ciência moderna, que o ser humano como um todo (sujeito pensante e teorizador com todos os meios formais, conceituais, etc.) é parte e até produto que chega à existência em determinado momento da evolução cósmica. A dimensão teórica é então algo que surgiu no decurso da evolução.

Essa ontologia supõe, em segundo lugar, uma mudança de perspectiva do sujeito para o Ser. Se os seres humanos fazem parte do mundo (da natureza ou do Ser), tudo e cada coisa que eles fazem, realizam, etc. faz parte também do mundo. A dimensão teórica é, pois, um palco ontológico ${ }^{32}$. Essa mudança de perspectiva é tão radical que pode ser entendida como uma inversão da "virada copernicana" (para o sujeito) de Kant. Podemos caracterizar essa nova virada assim: conhecimento (conceitualização, teorização) é primaria ou fundamentalmente algo que ocorre na natureza ou no mundo ou no Ser e não algo efetuado por um sujeito ${ }^{33}$. Conhecimento é o modo como a natureza ou o mundo manifesta ou expressa a si mesmo. É isso que aparece no operador "é o caso que p". Na virada copernicana teríamos que dizer:"A partir da perspectiva

31 Truísmo: afirmação assumida como verdadeira e transformada em atitude fundamental. Cf. ES, 536 32 ES, 536

33 Naturalmente não se nega que o conhecimento seja algo efetuado por um sujeito, mas sim que ele seja primaria e fundamentalmente efetuado por um sujeito. 
da subjetividade transcendental é o caso que o sol esquenta a pedra". Pelo contrário, o operador "é o caso que..." é o operador teórico absolutamente universal, que não está submetido a nenhuma restrição. É assim como Puntel elabora o quadro referencial teórico constituído por uma linguagem, uma semântica e uma ontologia.

3.2. Uma vez determinado plenamente o quadro teórico referencial, (o que o título do livro chama "Estrutura"), podemos desenvolver a teoria do ilimitado universo do discurso, (indicada no titulo com a expressão “Ser"), pois, como foi anunciado no título, o Ser se mostrará como a unidade dessas duas dimensões. Porém, entre as duas dimensões há uma assimetria fundamental. Enquanto a dimensão das estruturas pode, em grande medida, ser exposta puramente como tal (como de fato foi feito), a dimensão do Ser não pode ser nem minimamente articulada sem recorrer à dimensão estrutural. Pois "articular" não significa outra coisa senão apreender e apresentar as estruturas do Ser ou o Ser em sua estruturalidade ${ }^{34}$. Tampouco podemos simplesmente "aplicar" as estruturas ao Ser, pois esse termo poderia sugerir uma relação puramente exterior entre as duas dimensões, o que não é o caso. Pois tomadas isoladamente, as duas dimensões são puramente abstratas num sentido bem determinado. Estruturas sem Ser permanecem sem realização e, com isso, em certo sentido, vazias, pois lhes falta aquilo que, primariamente, lhes confere sentido. Ser sem estruturas permanece uma massa amorfa. A tarefa filosófica consiste em evidenciar a "interpenetração" das duas dimensões. Com isso consegue-se captar e expor as estruturas realizadas e o Ser estruturado de modo que transpareça a sua unidade fundamental ${ }^{35}$.

Como conceber então o ilimitado universo do discurso? Este, dizíamos antes $^{36}$, é a totalidade do que é dado. Embora a linguagem natural não possa ser a linguagem teórica, ela nos apresenta inicialmente o universo do discurso como dado universal. O mundo se apresenta numa determinada maneira, i.é, dotado de uma certa estruturalidade que nos é familiar: primeiro aparecem os âmbitos da natureza física ou anorgânica, o domínio da natureza orgânica, a dimensão humana com todas suas subdimensões: a dimensão dos entes humanos individuais, das pessoas humanas, a subdimensão da intersubjetividade ou social, a da vida prática (ética, política, direito), a da estética, a subdimensão da idealidade (ideias, teorias), a da história universal, a das religiões, etc. 
Do ponto de vista da linguagem natural, esse conjunto complexo é bem estruturado. É o grande dado pré-teórico, o universo do discurso pré-teórico tal e como a filosofia o encontra no início de sua aventura teórica. A tarefa principal da filosofia consiste então em examinar criticamente esse imenso dado natural pré-estruturado e elevá-lo à clareza teórica. A clareza teórica, em sua completa determinidade, é, como já vimos, a dimensão da verdade. Os dados, tal e como se apresentam na linguagem natural são somente candidatos à verdade. Dado é, pois, um termo técnico: é uma entidade lingüística, uma sentença prima, que expressa uma proposição prima, que, inicialmente, só tem o estatuto de "candidato à verdade", i. é, uma proposição prima a ser examinada, podendo, portanto, ser rejeitada.

A tarefa filosófica se configura como a elaboração da teoria desse todo ou como a teoria do Ser como tal e em seu todo. Trata-se da tarefa de mostrar a dimensão universal do Ser. Para isso, o autor propõe três vias de acesso, que são propriamente três aspectos de um único e abrangente empreendimento.

A $1^{\text {a }}$ mostra a dimensão universal do Ser como a dimensão pressuposta e articulada por toda sentença teórica. ${ }^{37}$

A estrutura da sentença teórica foi descrita antes ${ }^{38}$ como " $(\mathbf{T} \varphi)$ : $X$ é o caso que $\varphi$ ". Trata-se agora de interpretar o X que aparece no operador. A tese defendida pelo autor é: $X$ não é nenhum sujeito, mas constitui um indicativo geral de uma dimensão que se articula de modo indireto em todas as sentenças teóricas. ${ }^{39}$ Essa dimensão é o ilimitado universo do discurso, a dimensão absolutamente universal do teoricamente articulável, que pode ser designada como a dimensão primordial do $\operatorname{Ser}^{40}$. Primordial significa que a dimensão absolutamente universal do Ser, indicada pelo $\mathrm{X}$ do operador, não se limita ao Ser objetivo, oposto à dimensão estrutural. Ela abrange todos os casos particulares, individuais, do universo do discurso. E se perguntarmos como estão inter-relacionados todos esses casos, teremos que responder: o ponto comum mais profundo a todos os casos é que eles são, originaria e fundamentalmente, casos de Ser e do Ser (atual e possível) ${ }^{41}$. Daí resulta que

$37 \mathrm{SeD}, 177 \mathrm{ES}, 538$

38 Cf. p.7

39 Em alemão o X aparece como es: "es regnet", em inglês como it: "it is raining"; em francês como il: "il pleut". Mas tal partícula é tacitamente pressuposta na língua portuguesa "(...) chove”, "(...) é o caso que”. Neste caso poderíamos dizer: "X é o caso de tal modo que". Podemos interpretar essa palavra como indicação linguística de uma dimensão não caracterizada mais precisamente. No contexto teórico da filosofia sistemática é possível entender o "X" ("es", "it", "il”) em formulações do tipo"X é o caso de tal modo que assim e assim" como indicação universal não específico do mundo (da realidade, do universo, do Ser). (Cf, ES, 538)

40 Cf. SeD, 180

$41 \mathrm{SeD}, 180$ 
o simples uso do operador teórico em qualquer sentença declarativa revela e explicita a dimensão primordial do Ser.

A $2^{\mathrm{a}}$ via mostra a coextensionalidade intencional do espírito humano com o universo ilimitado do discurso.

A partir da dimensão primordial do Ser, pressuposta e articulada por toda sentença teórica, poderiam ser explicitadas todas as dimensões do Ser. Pois com o quadro teórico referencial é possível desenvolver teorias filosóficas de cada âmbito do Ser. De fato Puntel as desenvolve no cap. 4 de Estrutura e Ser com o título: "Sistemática do Mundo"42, que aqui não podemos tratar. Podemos, entretanto, desenvolver a teoria do ilimitado universo do discurso como tal e em seu todo. Como? O ilimitado universo do discurso pode ser articulado a partir de um dos momentos estruturais mais centrais do espírito humano. Esse momento estrutural é denominado aqui de "coextensionalidade intencional do espírito humano com o universo ilimitado do discurso" 43 .

Esta coextensividade é um constituinte básico do espírito humano. A partir dele é possível articular todas as interconexões, das mais simples até as mais complexas, até a interconexão de todas as interconexões, a saber, o Ser mesmo. Este processo de progressão pode acontecer porque o ser humano "já sempre" se encontra no ponto de chegada ${ }^{44}$. Esta é a reinterpretação do axioma aristotélico-tomista "anima est quodam modo omnia" e do célebre dito de Pascal: "O homem ultrapassa infinitamente o homem". Isso significa com outras palavras: não é a dimensão universal que é considerada e determinada a partir do homem, mas, ao contrário, é o homem que é determinado a partir da perspectiva universal como aquilo que ele na verdade é.

$3^{\mathrm{a}}$ via: A interconexão de todas as interconexões ou a interconexão mais abrangente como a dimensão absolutamente universal do Ser primordial..$^{45}$

O terceiro momento nos levará à dimensão do Ser primordial. Partindo das entidades simples: os fatos primos simples ou estruturas ontológicas simples, trata-se de um procedimento que consiste em ir explicitando paulatinamente todas as estruturalidades ou interconexões até chegar à estruturalidade de todas as estruturalidades ou interconexão de todas as interconexões.

42 Puntel entende mundo como aquela dimensão do universo ou do Ser (em seu todo) que deve ser concebida como a interconexão das áreas (tratadas no cap. 4): "mundo natural", "mundo humano" (antropologia fil., Ética - agir moral e valores morais), "mundo estético", "totalidade do mundo". Cf. ES, 330 
Começamos com a "macroestrutura" ontológica do mundo ou polo objetivo do universo do discurso. Os dados, tal e como foram recebidos pela linguagem natural, são concebidos, inicialmente, como sentenças primas que expressam proposições primas, e estas, quando verdadeiras, como fatos primos. Fatos primos são estruturas ontológicas primas, chamadas aqui de interconexões. Estas estruturas são as menores de todas as interconexões. Tomadas isoladamente, elas são abstratas. As estruturas complexas (concretas) são configurações de fatos primos. Partimos, então, das configurações chamadas de "indivíduos" como seres vivos ou pessoas. Assim entendido, um indivíduo, por ex., um ser humano, é uma estrutura ou configuração altamente complexa. Temos aqui uma primeira interconexão.

Os indivíduos, por sua vez, estão integrados em interconexões mais amplas: estão conectados com a natureza e todos os seus fenômenos, estão conectados com os indivíduos de sua espécie. Todos eles formam um domínio do mundo. Temos, então, uma segunda interconexão que constitui e define $u m$ domínio.

Porém, há muitos domínios interconectados entre si. Temos assim uma interconexão abrangente que define o mundo. Mundo é a interconexão compreensiva objetiva propriamente dita da dimensão do universo do discurso, à qual se refere a dimensão das estruturas fundamentais.

E agora surge a pergunta decisiva: como deve ser compreendida a relação entre as duas dimensões: a dimensão "teórica" das estruturas e a dimensão do mundo ("polo objetivo")? É claro que essa relação só é possível se entre ambas as dimensões for pressuposto algo fundamental em comum, i.é, uma unidade, que justamente possibilite a "conjunção" das duas. A dimensão original ou metadimensão que abrange as duas e possibilita a sua relação mutua é designada aqui de dimensão do Ser, entendendo por Ser não o "Ser objetivo", mas o Ser primordial, que abrange as duas dimensões ${ }^{46}$. O Ser primordial aparece aqui como a interconexão absolutamente universal ou interconexão de todas as interconexões.$^{47}$ Fora dessa dimensão absolutamente universal ou dimensão originária nada é imaginável, concebível, tematizável, etc.

46 Sobre a discussão mais pormenorizada sobre a dimensão original ou primordial do Ser e a tese da pluralidade de mundos possíveis, ver ES, 573-579

47 É importante observar que a dimensão primordial do Ser não é idêntica ao esse - actus essendi de Tomás de Aquino. Ela não isola o ato de Ser, como faz o Aquinate, para elevá-lo à pura perfeição de todas as perfeições. Ela articula as interconexões cada vez mais amplas até chegar à interconexão de todas as interconexões. Esta última é que é designada como dimensão primordial do Ser. 


\section{O Ser como tal e em seu todo ou o Ser como bidimensionalidade}

Conseguida a unidade fundamental entre a dimensão teórica e o ilimitado universo do discurso, i, é, a dimensão do Ser primordial, surge a pergunta: como deve ser compreendida mais exatamente a dimensão absolutamente universal do Ser? Ela será compreendida como o Ser como tal e em seu todo. Uma teoria do Ser só é adequada se for entendida nessa diferenciação e qualificação. Ser como tal porque se trata do tema absolutamente singular do Ser (e não dos entes nem do ente supremo). Ser em seu todo, porque o Ser como tal não é atingido quando se fica nele de modo abstrato, fazendo dele uma espécie de entidade platônica abstrata. Para isso, é necessário tematizar a relação Ser e entes. Porém, Ser em seu todo não é a totalidade extensiva ou soma dos entes, porque então ele seria um ente a mais. Ser em seu todo tem que ser entendido positivamente como Ser-em-sua-relação-com-os-entes, porque todo ente é uma determinada forma de tudo o que se chama "Ser"48 Isto o autor o enfatiza muito contra Heidegger. Mas é claro que as duas qualificações (Ser como tal e Ser em seu todo) não podem ser separadas, porque Ser abrange tudo. ${ }^{49}$

Qual seria a pergunta adequada com respeito ao Ser como tal? Espontaneamente surge a pergunta: o que é o Ser como tal? Porém, a pesar de sua aparente evidência, ela não cabe neste momento, pois as perguntas com a forma: o que é...?, são significativas quando permitem esperar uma resposta que articula algo que diferencia o objeto da pergunta de outras coisas que podem ser indicadas claramente, por ex.: o que é o átomo? Mas de que se diferenciaria o Ser, se fora do Ser não há nada? A pergunta: o que é o Ser como tal, não é, pois, significativa. A pergunta adequada em relação à dimensão do Ser só pode ter a forma "como": como tem que ser compreendido ou explicitado o Ser? ${ }^{50} \mathrm{E}$ com isso é dado também o procedimento adequado a uma teoria do Ser: a explicação. Esta é compreendida como um procedimento analítico/ argumentativo/apurativo da coisa ${ }^{51}$. Na execução do procedimento, os três fatores atuam, mas não em igual medida. Dependendo do momento da explicação, atua em primeiro plano uma análise do significado linguístico ou uma argumentação ou a articulação conclusiva da coisa.

Na explicação da primeira qualificação do Ser se trata de explicitar os momentos estruturais imanentes mais fundamentais do Ser como tal. As características mais gerais são a inteligibilidade absolutamente universal, 
a coerência ou estruturalidade universal, a expressabilidade universal, a bondade universal e a beleza. ${ }^{52}$

$\mathrm{Na}$ explicação da segunda qualificação Ser em seu todo aparece um dos pontos originais da teoria de Puntel, porque se perguntamos quais seriam os conceitos que possibilitam a compreensão de todas as interconexões surgem as modalidades como a chave para a explicação do Ser em seu todo: necessidade, possibilidade, contingência ${ }^{53}$. As modalidades representam uma das maiores potencialidades de inteligibilidade do pensamento humano, porque elas são, no fundo, modos pelos quais se manifesta a dimensão do Ser propriamente dito.

A partir delas, Puntel coloca a questão: o "Ser em seu todo" é contingente, i. é, possui um estatuto contingente? O sentido da questão visa refutar a tese que afirma que tudo o que existe é contingente. Da falsidade da tese decorre imediatamente que o Ser em seu todo possui uma dimensão absolutamente necessária. Trata-se, pois, de uma demonstração indireta ou reductio ad absurdum.

Se absolutamente tudo, e assim a dimensão primordial do Ser, fosse contingente, então poderia ter sido que nem a dimensão do Ser nem qualquer elemento pertencente a ela (algum "ente") teria chegado a ser, i. é, o nada absoluto seria possível. A consequência implicativa inevitável da tese: tudo é contingente, é a possibilidade do nada absoluto. Ora, o nada absoluto não é possível, logo, nem tudo é contingente, i. é, uma dimensão necessária do Ser tem de ser aceita.

O nada absoluto não é possível, em primeiro lugar, porque ele é um conceito impensável, pois é autocontraditório e, portanto, um pseudoconceito. Com efeito, quando se quer "pensá-lo", i. é, determiná-lo, de algum modo, atribui-se a ele justamente o que ele exclui, qualquer determinação. Tentase determinar o conceito nomeando "algo" qualquer, porém todo e qualquer algo, como quer que ele seja, é um determinado modo de ser. A rigor, do nada absoluto nem se poderia falar, a não ser de modo paradoxal, justamente para mostrar indiretamente sua absurdidade. Até o conceito de possibilidade do nada absoluto é um conceito radicalmente autocontraditório, pois "possibilidade" é sempre "possibilidade de ser".

Em segundo lugar, a tese: tudo é contingente, implica uma segunda consequência, que os entes poderiam "passar" do nada absoluto ao ser, ou, como vemos que existem entes, que eles, de fato, "passaram" ao Ser. Porém, 
a mera ideia de uma "transição" (mesmo que só possível) do impensável nada absoluto para o Ser é igualmente uma pseudoideia impossível e, portanto, totalmente absurda. Do nada absoluto nada pode surgir.

Portanto, se tudo não pode ser contingente, temos que admitir uma dimensão absolutamente necessária do $\mathrm{Ser}^{54}$. O termo "absolutamente" significa que essa dimensão necessária do Ser é independente de qualquer outra coisa que a pudesse condicionar. ${ }^{55}$ Por sua vez, como a existência de entes contingentes é um fato, pois eles são, mas poderiam não ter sido, por surgirem e desaparecerem, segue-se, igualmente, que existe uma dimensão contingente do $\mathrm{Ser}^{56}$, que só pode ser entendida como subordinada àquela.

Da demonstração desenvolvida resulta que se deve assumir uma dimensão absolutamente necessária do Ser e uma dimensão contingente do Ser. Por conseguinte, a dimensão original ou primordial do Ser (o Ser em seu todo), concebida mais exatamente ou de modo mais determinado, constitui a bidimensionalidade do $\mathrm{Ser}^{57}$.

\section{Explicitação da relação entre as duas dimensões do Ser}

Partindo da dimensão primordial do Ser como bidimensionalidade, surge a nova tarefa de explicitar a relação entre as duas dimensões necessária e contingente do Ser. E, de novo, é a coextensividade intencional do espírito humano com o todo, o universo, o Ser que possibilita compreender adequadamente essa relação. A dimensão necessária do Ser terá que ser concebida como Ser espiritual, absolutamente necessário, i.é, dotado de inteligência, vontade e liberdade, e como Ser absoluto criador.

A $1^{\mathrm{a}}$ determinação é facilmente compreensível. Se a dimensão necessária do Ser não fosse espiritualmente constituída, teríamos entes contingentes intencionalmente coextensivos com o Ser como tal e em seu todo, i. é, espiritualmente constituídos, e a dimensão necessária do Ser constituída de modo puramente abstrato ou meramente natural, i.é, inferior ao espírito humano. Como poderíamos então explicar a relação de dependência deste último do Ser necessário? O autor expressa esse estado de coisas na forma de um princípio fundamental (princípio de grau ontológico) válido para toda ontologia que queira fazer justiça ao caráter específico dos diferentes âmbitos 
do Ser: "Algo de grau ontológico mais elevado ou superior não pode vir a ser ou ser explicado a partir de algo de grau ontológico mais baixo ou inferior" ${ }^{58}$. Mas por ser esta dimensão absolutamente necessária, ela tem que ser concebida como constituída de tal modo que a dimensão contingente do Ser seja explicável a partir dela. Portanto, a dimensão absolutamente necessária do Ser tem que ser concebida como Ser espiritual ${ }^{59}$.

A $2^{\text {a }}$ determinação da dimensão necessária do Ser como absoluto criador retoma a ideia de criação, mas ela é reinterpretada, entendida, e avaliada, no quadro da concepção do Ser como tal e em seu todo, o que representa uma grande novidade. Primeiro, porque a ideia de criação tem um estatuto único, que tem que ser salientado e explicitado. A partir da distinção entre dimensão absolutamente necessária e dimensão contingente do Ser e da explicitação da primeira como Ser espiritual, a ser pensado como liberdade absoluta, surge a pergunta: como tem de ser concebida a relação entre o Ser livre absolutamente necessário e a dimensão contingente do Ser?60

$\mathrm{O}$ que define os entes contingentes é que eles são, mas poderiam não ser, i. é, não são necessariamente. Isso significa que eles não são a partir de si mesmos ou não são explicáveis a partir deles mesmos. Ora, se os entes poderiam não ter sido, como eles chegaram a ser? Se não foi por eles mesmos, foi pelo Ser absolutamente necessário. Mas como este é o Ser livre absolutamente necessário, o que entra em jogo imediatamente, ao responder à pergunta colocada, é a liberdade. A dimensão contingente do Ser chegou ao Ser pela liberdade absoluta do Ser necessário, e isso de modo absoluto, i. é, sem pressupor nada precedente ou subjacente.. A ideia de criação adequadamente articulada significa então "o absoluto pôr no Ser a dimensão contingente do Ser realizado pelo Ser livre absolutamente necessário" 61

Ela é uma ideia absolutamente única que articula exclusivamente a relação do Ser absolutamente necessário como criador com a dimensão contingente do Ser. Isso significa: a dependência total dos entes contingentes em relação ao Ser absoluto tem o estatuto de ser-criado. O mundo criado como um todo é totalmente dependente do Ser absoluto. Mas como tal o mundo criado é um todo inteiramente estruturado com suas próprias leis e potencialidades. Isso significa: tudo o que surge ou é produzido no interior da dimensão contingente do Ser não é criado no sentido exposto, pois tudo o que surge ou é produzido

58 ES, 603

59 Para tudo isto, ver ES, 599-603. Sobre o problema da compatibilidade do PGO e as teorias da evolução, ver ES, 603-607

$60 \mathrm{SeD}, 229$

$61 \mathrm{SeD}, 229$ 
no interior do mundo, pressupõe sempre algo precedente (seja o que for este algo). Esta é uma das causas dos muitos mal-entendidos difundidos sobre a ideia de criação ${ }^{62}$. É por isso também que a pergunta pela criação não pode ser respondida através de uma explicação do por quê?, mas de uma explicação do como, porque as perguntas por quê só são significativas quando se fazem com referência a uma interconexão dentro de uma dimensão já pressuposta, que não é tematizada. A pergunta pela criação é uma pergunta pela dimensão mesma, i.é, pela dimensão contingente do Ser como tal e em seu todo, e não por alguma interconexão dentro dessa dimensão contingente do Ser. 